\title{
Numerical Analysis of a Hydrodynamic Herringbone Grooved Journal Bearing
}

\author{
D. Souchet, ${ }^{1}$ A. Senouci, ${ }^{1}$ H. Zaidi $\left(D,{ }^{1}\right.$ and M. Amirat ${ }^{2}$ \\ ${ }^{1}$ Institut P', CNRS-Université de Poitiers-UMR 3346, SP2MI, Bd Marie et Pierre Curie, \\ BP 3017986962 Futuroscope Chasseneuil Cedex, Poitiers, France \\ ${ }^{2}$ Smart Structures Laboratory (SSL), DME, Technology Institute, University Center D’ain Témouchent, P.O. Box 284, 46000, \\ Aï Témouchent, Algeria \\ Correspondence should be addressed to H. Zaidi; hamid.zaidi@univ-poitiers.fr
}

Received 8 March 2020; Revised 21 May 2020; Accepted 8 July 2020; Published 3 December 2020

Academic Editor: Chuan-Yu Wu

Copyright (@ 2020 D. Souchet et al. This is an open access article distributed under the Creative Commons Attribution License, which permits unrestricted use, distribution, and reproduction in any medium, provided the original work is properly cited.

\begin{abstract}
In hydrodynamic lubrication, at very high rotational speed, the phenomenon of axial fluid leakage is often present. This can involve an increase of shear stress in the contact and consequently a considerable increase of the temperature. For that and in order to solve this problem, we took interest in the herringbone grooved journal bearings. The researches made before on these types of groove bearing have shown that they present a good dynamical behavior with a low eccentricity and a low axial flow. In this paper, a numerical study of a herringbone journal bearing operating behavior, under laminar and isothermal regime, is presented. The theoretical model, based on the classical Reynolds equation, is used. In order to include the film rupture and reformation, the Reynolds equation is modified using a mass conservative algorithm. To understand the behavior of these herringbone grooved journal bearings well, numerical modeling, using finite element method, has been developed. Various geometrical shapes of the herringbone grooved journal bearings have been analyzed, allowing us to limit the fluid leakage problem, by working particularly on the contact form.
\end{abstract}

\section{Introduction}

Herringbone grooved journal bearing is one of the best alternatives used in business machines and other applications, due to their improved stability characteristics and their implication to reduce the fluid leakage effect. Studies which treat this type of groove bearing are not very plentiful. Nevertheless, we can include the work of Hirs [1], in 1965. He has used this type of groove to analyze the bearing load and the stability in the hydrodynamic groove bearings for an incompressible fluid and a flow supposed isotherm. Three different cases have been developed: a complete herringbone grooved journal bearing, a partial herringbone grooved journal bearing, and a helicoid groove bearing. In the same way, Bootsma [2] in 1977 has realized various experiments on herringbone grooved journal bearings with different geometrical characteristics. He has used incompressible fluids with different properties. For each fluid and different eccentricities, he looked for the rotational speed value where the fluid flow is null. He indicated that it is impossible to have a relation between the eccentricity and the rotational speed to cancel the axial flow; however, a judicious choice of the geometrical parameters and the rotational speed can prevent the flow leakage for certain eccentricities. All these different works were made in order to eliminate the necessity to have an additional sealing system. Also they have an important interest from mechanical, economical, and ecological point of view [1-9].

In order to correlate the experimental results, numerical studies using the finite element method (FEM), the finite volume method, and the finite difference method have been investigated. Earlier, in 1969 Reddi [3] published the FEM of an incompressible lubricant fluid. Few years later, Hamrock and fleming [4] have developed a calculus model which permit the optimization of the geometrical parameters of a herringbone grooved journal bearing (slope, depth, width, etc.) in order to obtain a maximum bearing load. This method was improved in 
1972 by Smalley [5] who has developed a numerical method for all groove bearings. In 1994, Bonneau and Absi [6, 9] have analyzed aerodynamic journal bearings, featuring a small number of herringbone grooves using a finite element algorithm. They have presented results for herringbone grooved journal bearing with 4-16 grooves rotating with an arbitrary eccentricity and a maximum bearing number. In 2007 and in the same way, Wang [7] has investigated the bifurcation and nonlinear behavior of an aerodynamic journal bearing system taking into account the effect of stationary herringbone groove applying the finite difference method.

While there are few articles on herringbone bearings, there are more studies on bearings or seals using similar geometries, including propeller or viscoseals [10]. In 2015, Targaoui et al., [11] presented a detailed study of the propeller seals in isothermal regime. The numerical method used is the finite element method, using the algorithm developed by Hajjam and Bonneau [12] for the determination of the rupture and the reformation of the film. The results are compared to those of Boon and Tall [13]. In 2017, Souchet et al. [14] developed a model for different flow regimes in the case of a propeller joint. The results are compared with the experimental results of Luttrull [15] and make it possible to validate the mathematical and numerical models chosen as well in laminar mode as turbulent [16-19].

The applied Reynolds equation assumes fully flooded clearance gap. This is not true in reality. The model of Jacobson is the first model that inspired the universal equation method of Reynolds to take into account the phenomenon of cavitation (the active and inactive zone at the same time). To take into account the reformation of the film and ensure the continuity of the mass, Jakobsson, Floberg, and Olsson developed, in the 1960s, a boundary condition of mass-conserving cavitation, called after the JFO boundary condition which separates the active and inactive area, but unfortunately, its complexity made it difficult to implement digitally, because the location of the cavitation limits is not known a priori. Hajjam and Bonneau [12] developed a modified version of the Reynolds equation and introduced a single variable from which the pressure fields and a complementary variable are reconstructed. It is this model that was introduced here. The publications, written in part by Souchet et al. [11, 14], describe the Reynolds equation thus modified as well as the numerical algorithm of resolution $[11,12,14,19]$.

To minimize the problem of fluid leakage into systems and from models developed and validated with theoretical and experimental results on the viscoseals $[11,14]$, in this paper our study will be extended to different herringbone grooved journal bearing geometries, for an incompressible lubricant. The Reynolds equation will be solved by the finite element method (FEM). The pressure distribution and the fluid flow will be calculated and analyzed.

\section{Mathematical Modeling and Analytical Method}

2.1. Governing Equations. The herringbone grooved journal bearing is centered on a shaft or on boring with axial and radial eccentricities being null. The flow is supposed isotherm and laminar and the oil is incompressible. Different geometries of herringbone grooved journal bearing (Figure 1) were chosen.

Figure 1(a) is a classical herringbone grooved journal bearing with a herringbone angle of $45^{\circ}$ and a number of grooves $\mathrm{NG}=8$. It has a helicoid form which goes from the edges to the middle of the bearing. The Cartesian case of this type of bearing is clearly schematized on Figure 2 where $\mathrm{B}_{0}$ is the initial part of the shaft, $\mathrm{B}$ is the machined part, HG is the groove depth, and $\mathrm{C}$ is the radial clearance. In order to simplify our gait, the typical herringbone grooved journal bearing will be noted (case A). Under the same assumptions, grooves have been modeled on each edge of the bearing, Figure 1(b) (case B) with a width of groove supposed to be equal to $2 \mathrm{~mm}$. A circumferential groove was also modeled in the middle of the bearing, Figure 1(c) (case C), and in both the middle and each side of the bearing, Figure 1(d) (case D).

2.1.1. Modified Reynolds Equation. To simplify the computations, all mathematical expressions are deduced in the Cartesian coordinates. The shaft and the housing are developed in the $(x, z)$ plane plotted in Figure 2. The film thickness is according to the $y$-axis. As cited above, the new feature in this paper is on lubrication sealing devices. Indeed, in thin film theory, it is assumed that the fluid curvature could be neglected. This could find reason in the most important assumption that assumes the ratio of film thickness to radius of curvature to be of the order of $o$ $\left(10^{-3}\right)$.

In addition, the inertia effects are negligible and the regime is laminar. Hence, the Reynolds equation governing the incompressible, viscous, and Newtonian thin films flow is expressed by

$$
\frac{\partial}{\partial \mathrm{x}}\left(\frac{\mathrm{h}^{3}}{\mu} \frac{\partial \mathrm{p}}{\partial \mathrm{x}}\right)+\frac{\partial}{\partial \mathrm{z}}\left(\frac{\mathrm{h}^{3}}{\mu} \frac{\partial \mathrm{p}}{\partial \mathrm{z}}\right)=6 \omega \mathrm{R} \frac{\partial \mathrm{h}}{\partial \mathrm{x}}
$$

where $p$ and $h$ represent the pressure and the film thickness, respectively, $\omega$ the rotational speed, and $\mu$ the lubricant viscosity.

The setup of the sealing could be described by a separation phenomenon that occurs between liquid and ambient air. An adaptive model is presented as follows. It is a modified form of Reynolds equation (MRE) detailed in [12] that can be used in the whole domain both in the active and the inactive regions. In fact, the chosen mass conservative algorithm is mainly dedicated to the prediction of the breakdown or the reformation of the lubricating film. The considered MRE can be written as follows:

$$
F \frac{\partial}{\partial x}\left(\frac{h^{3}}{\mu} \frac{\partial E}{\partial x}\right)+F \frac{\partial}{\partial z}\left(\frac{h^{3}}{\mu} \frac{\partial E}{\partial z}\right)=6 \omega R \frac{\partial}{\partial x}(h+(1-F) E)
$$

where $E$ is a universal variable and $F$ a switch function that identifies the active and the inactive zone, such as 


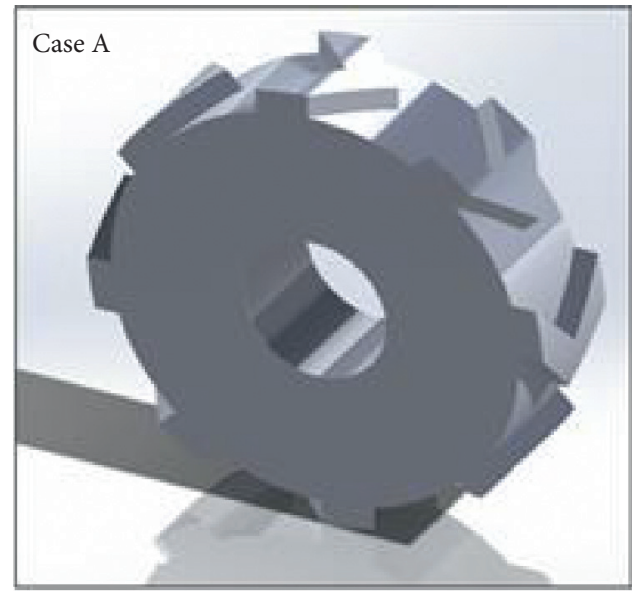

(a)

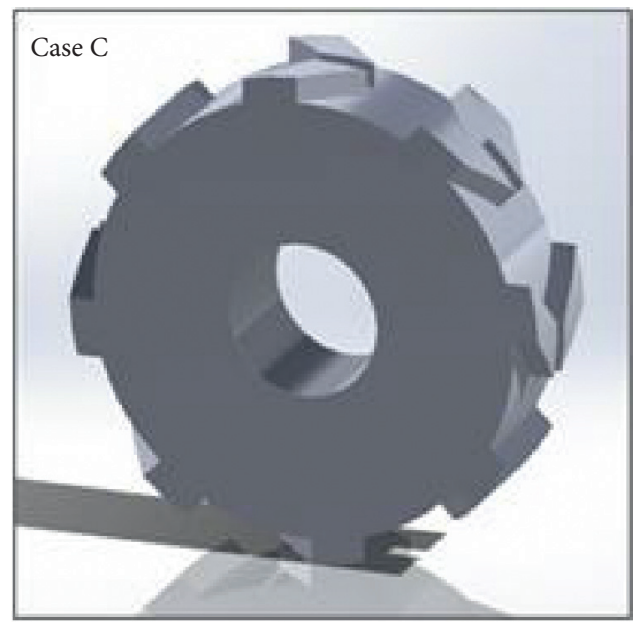

(c)

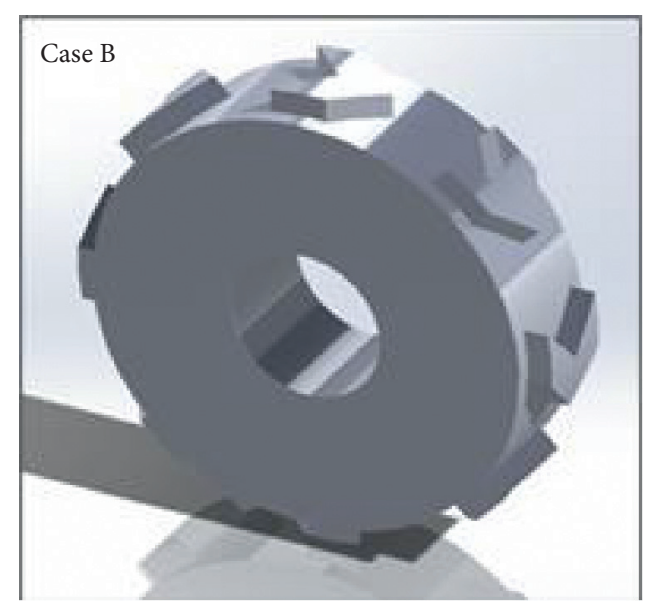

(b)

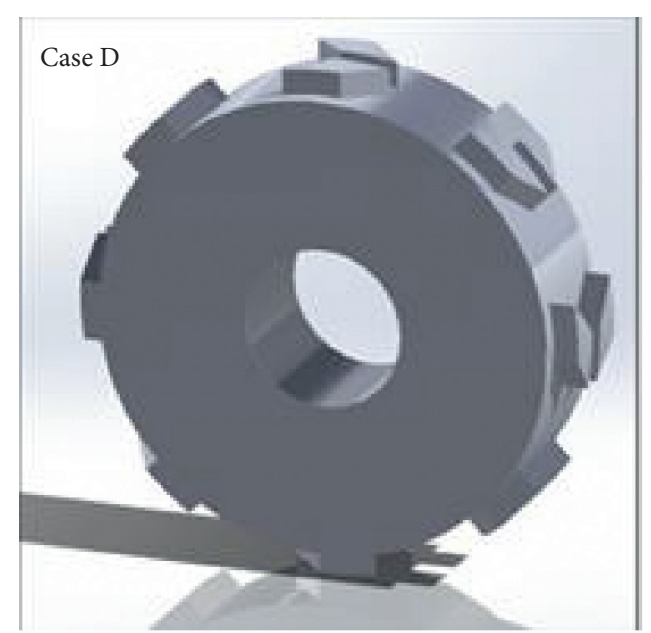

(d)

Figure 1: Herringbone grooved journal bearing shapes. (a) Case A. (b) Case B. (c) Case C. (d) Case D.

active zone: $\left\{\begin{array}{l}E=p \\ F=1\end{array}\right.$

inactive zone: $\left\{\begin{array}{l}E=r-h \\ F=0\end{array}\right.$, where $r=\rho / \rho_{0} h$.

$\rho_{0}$ is the lubricant density, $\rho$ represents the lubricant-gas mixture density, and $r$ is the "filling" coefficient that characterizes the level of filling of liquid [12].

The boundary conditions used for the resolution of the MRE are based on the separation of the active and inactive zones.

The boundary conditions that the MRE must satisfy are as follows:

In the outside boundaries of the domain, at $\mathrm{z}=0$ and $\mathrm{Z}=\mathrm{L}$, the pressure $p$ is set to the atmospheric pressure.

In order to respect the continuity of the $E$ function on the developed geometry, it is required, at $x=0$ and $x=\pi D$, that $E_{x=0}=E_{x=\pi D}$.

On the sealing boundary (breakdown), the so-called

Reynolds conditions are applied: $p=0$ and $d p / d x=0$.
One must also express the mass flow preservation, in stationary case:

$\left.\left(h^{3} / \mu U\right)(d p / d x)\right|_{x_{b}}=0$, where $x_{b}$ is the film breakdown point.

On the reformation film boundary, the mass flow preservation is given by

$\left.\left(h^{3} / \mu U\right)(d p / d x)\right|_{x_{r}}=0$, where $x_{r}$ is the film reformation point.

2.1.2. Numerical Solution and Numerical Algorithm. The problem is discretized using four-node quadratic linear elements. The finite element method has been chosen because it can be easily applied to film thickness discontinuities generated by the spiral grooves. The integral form of equation [1] defined on the domain $\Omega$ of the lubricant film is

$\int_{\Omega}\left(F\left[\frac{h^{3}}{\mu} \frac{\partial W}{\partial x}\left(\frac{\partial E}{\partial x}\right)+\frac{h^{3}}{\mu} \frac{\partial W}{\partial z}\left(\frac{\partial E}{\partial z}\right)\right]-6 \omega R \frac{\partial W}{\partial x}[h+(1-F) E]\right) d \Omega$, 


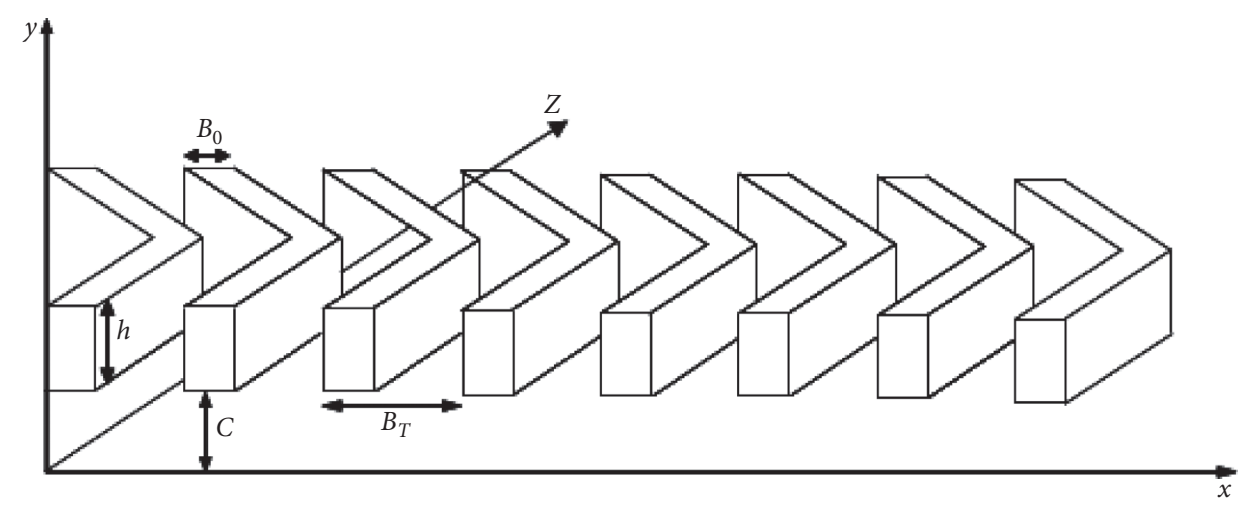

Figure 2: Cartesian form of case A.

where $W$ is a weighting function defined on $\Omega$. In the active zones $(F=1)$, the partial differential equation to be solved is elliptical (diffusion equation). In the inactive zones $(F=0)$, the equation is hyperbolic (convection equation). Therefore, in the active zones the weighting function will be equal to the interpolation function (Bubnov-Galerkin method), and in the inactive zones the weighting functions will be polynomial functions which are upwind decentered (Petrov-Galerkin method). It must be mentioned that in this equation the source term is integrated by parts in order to carry over the derivation onto the weighting function which enables us to correctly take into account the film thickness discontinuities. However, care is taken in order to precisely have a coincidence between the discontinuities and the element borders.

The numerical algorithm in represented. The wetted area in the each side of the herringbone $L$ is evaluated by an iterative algorithm. The outlet flow rate is calculated starting from an initial value, measured from the seal inlet. If the value is positive, the length of the herringbone or sealing length is increased by the length of an element in the flow direction $(z)$. If the value is negative, the length is decreased by the length of an element. The convergence is attained when, for two consecutive iterations, the flow rate changes from positive to negative or vice versa. The present algorithm is generally based on the one proposed by Hajjam and Bonneau [12] and is described in Algorithm 1.

In relation to the stability state of the breakdown and reforming domain boundary, the convergence criterion is associated with the node number that changes state (active, inactive) between two successive iterations. This number must not exceed $2 \%$ of the total node number to declare the convergence.

Otherwise, it is interesting to underline that the numerical model used for the characterization of a herringbone bearing has been validated in the case of viscoseals in laminar and turbulent regime [14]. In the case of a laminar regime, the results on the optimal geometry [11] were compared with those of Boon and Tall [13]. The study in the case of a herringbone grooved journal bearing does not change in any way, in the mathematical and numerical modeling. The main difference is only that we have to manage both edges of the landing but the principle stays the same.

\section{Discussion}

We use, in the different calculus, the values of grooves number and the grooves angle given in the case of aerodynamic herringbone $[6,9]$ and these given in the case of viscoseals [13-16].

The data of the operating conditions are summarized in Table 1.

Figure 3(a) gives the pressure repartition for a typical case (case A), obtained for a rotational speed of $25000 \mathrm{rpm}$ and $C=\mathrm{HG}=500 \mu \mathrm{m}$. It shows regular forms of pressure followed by regular depression forms. These regular forms guarantee not having an overload on the remainder structure. The maximum pressure is defined at $0.0579 \mathrm{MPa}$; this value is relatively low compared to results found in literature [7], probably due to the supposed value of the given lubricating film thickness. However the minimal pressure is given at $-0.01140 \mathrm{MPa}$ and it ensures that we avoid the cavitation phenomena.

For case B, a slight decrease of the maximum pressure (Figure 3(b)) around $0.0511 \mathrm{MPa}$ can be noticed. Though, there is no considerable effect on the minimal value of the pressure compared with the first case $(\approx-0.0137 \mathrm{MPa})$.

Figure 4(a) shows the pressure repartition for case C obtained under the same conditions as before. The maximum pressure is localized on both sides of the middle of the bearing and it is around $0.0411 \mathrm{MPa}$. In the same way, Figure 3(a) gives the repartition of pressure for case $\mathrm{D}$ with the maximum pressure noticed around $0.0345 \mathrm{MPa}$. The minimal values of pressure for both cases are quasisimilar.

In Figure 5, we have regrouped the pressure repartition and the correspondent film thickness versus the number of nodes for the four cases in the radial axis for one element. As reported before, the maximum pressure is higher for case A and it is lower for case D comparing with the other cases. Note the presence of two zones corresponding to grooves modeled in each side of the bearing cases (B and D). Their presence should ensure that the pressure falls rapidly and help to have a gradient of 


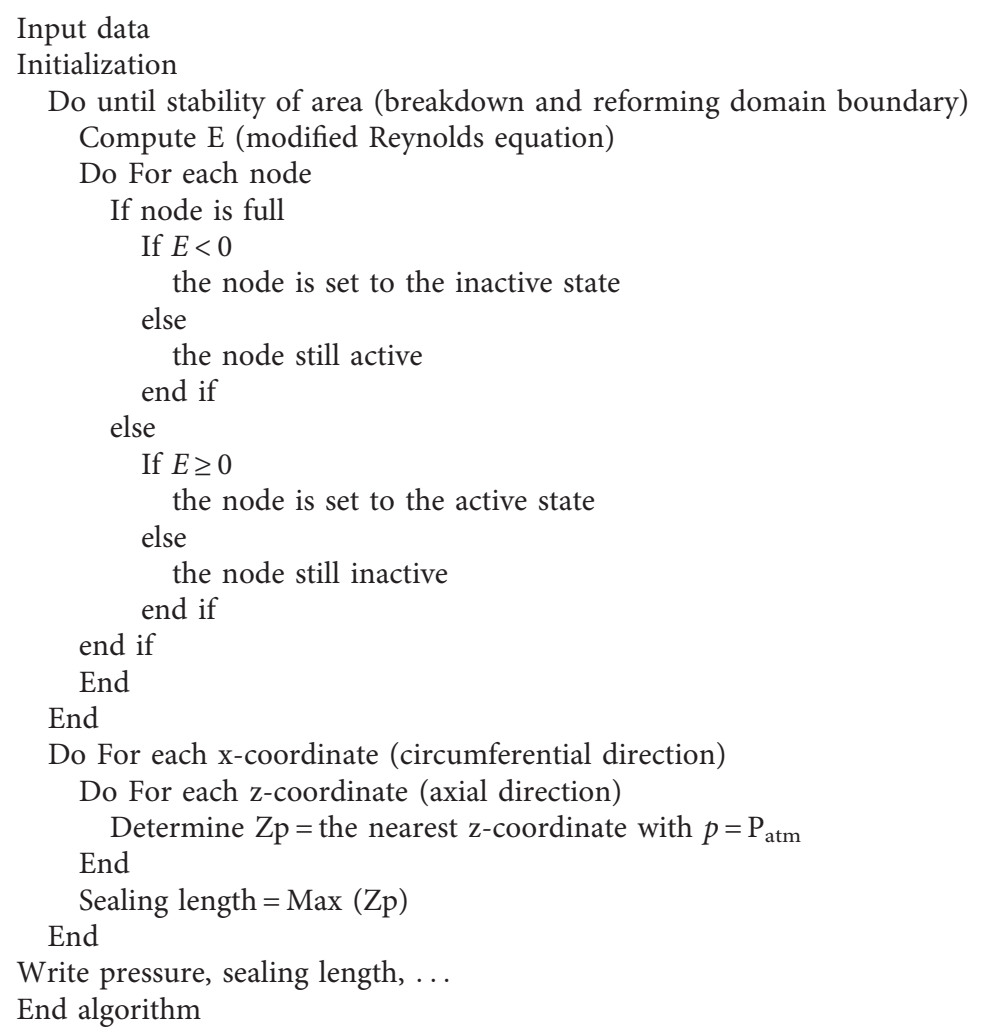

Algorithm 1: Algorithm proposed by Hajam and Bonneau [12].

TABLE 1: Data of the operating conditions.

\begin{tabular}{lcc}
\hline Diameter & D & $50 \mathrm{~mm}$ \\
Width of herringbone & $\mathrm{w}$ & $20 \mathrm{~mm}$ \\
Radial clearance & $\mathrm{C}$ & $500 \mu \mathrm{m}$ \\
Depth of groove & $\mathrm{HG}$ & $500 \mu \mathrm{m}$ \\
Lubricant & $\mu$ & Oil ISO VG $32(\mathrm{MPas})$ \\
Rotational speed & $\omega$ & $2000 \mathrm{rpm}$ to $25000 \mathrm{rpm}$ \\
Number of grooves & $\mathrm{NG}$ & 8 \\
Herringbone angle & $\beta$ & $45^{\circ}$ \\
\hline
\end{tabular}

pressure near zero on the edge. In the same way, the presence of a circumferential groove in the middle of the bearing drops the pressure.

3.1. Effect of the Rotational Speed. In order to investigate the effect of the rotational speed, some numerical results will be presented and discussed. The data remains similar to precedent except the rotational speed which varies between $2000 \mathrm{rpm}$ and $25000 \mathrm{rpm}$.

Figure 6 gives the influence of the rotational speed on the maximum pressure for different herringbone grooved journal bearings. For all cases, the pressure increases with the rotational speed. Nevertheless, the pressure is lower in both cases $\mathrm{C}$ and $\mathrm{D}$ compared with the other geometries, due to the presence of the circumferential groove in the middle of the bearing. As for case B, the obtained values are lower than those of case A. Furthermore, the presence of circumferential grooves in each side of the bearing accentuates also a little the drop of pressure. Obviously, it is judicious to note that the fluid flow remains null whatever the speed for both cases B and D is. Furthermore, the friction torque values were found to be much close for the four geometries.

3.2. Effect of the Herringbone Angle and the Number of Grooves. Taking into account the initial data given in Section 3.1 and the case of a typical bearing, case A, under a constant rotational speed of $25000 \mathrm{rpm}$, in this section we will investigate the effect of the herringbone angle and the number of grooves varying successively the angle from $30^{\circ}$ to $90^{\circ}$ and the number of grooves (NG) from 6 to 12 .

Figure 7 gives the influence of the groove and/or the herringbone angle on the maximum pressure for different number of grooves. The results show a slight decrease of the maximum pressure with the increasing of the herringbone angle. Further, for bearing with 6 grooves the pressure is sensibly higher than those with 12 grooves. Therefore, two different zones can be noticed: the first one for angles from $30^{\circ}$ to $45^{\circ}$ where the pressure is maximal for all cases (note that at $35^{\circ}$ for $\mathrm{NG}=6, \quad P_{\max }=0.066228 \mathrm{MPa}$; for $\mathrm{NG}=8$, $P_{\max }=0.059366 \mathrm{MPa}$; for $\mathrm{NG}=10, P_{\max }=0.055403 \mathrm{MPa}$; and for $\mathrm{NG}=12, P_{\max }=0.053020 \mathrm{MPa}$ ) and the second one for angles above $45^{\circ}$ where the pressure drops. Absi [9] has shown that the best performance of a herringbone grooved journal bearing, in the case of aerodynamic bearing,is obtained for a 


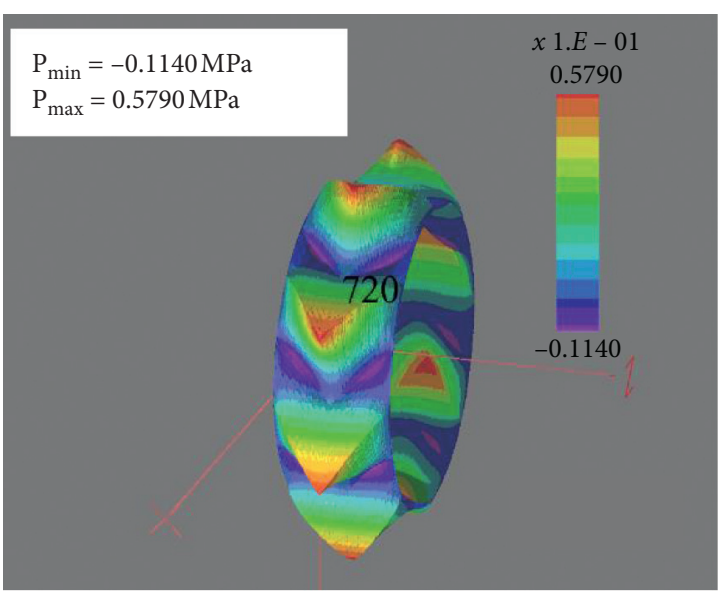

(a)

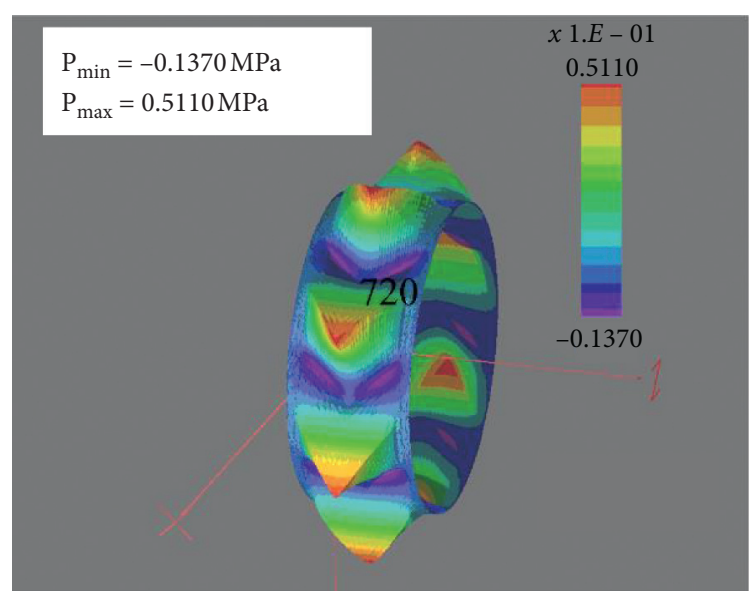

(b)

Figure 3: Pressure repartition (case A and case B, respectively). (a) Case A. (b) Case B.

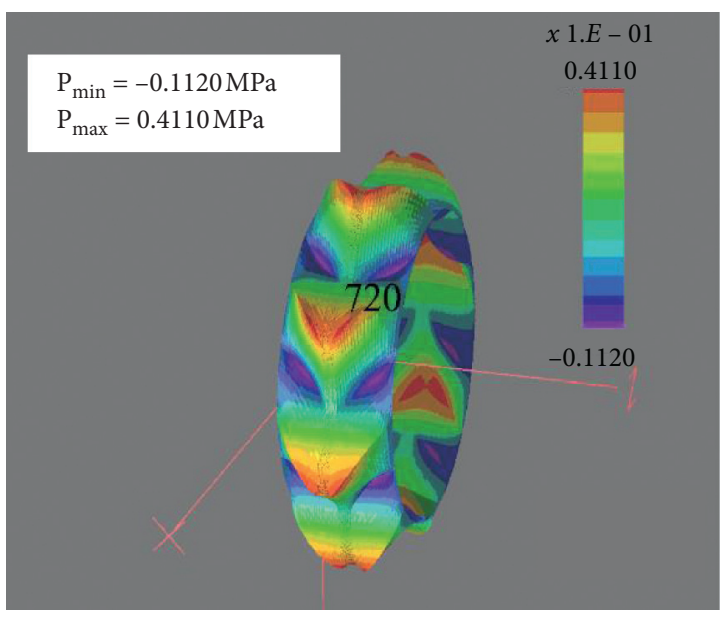

(a)

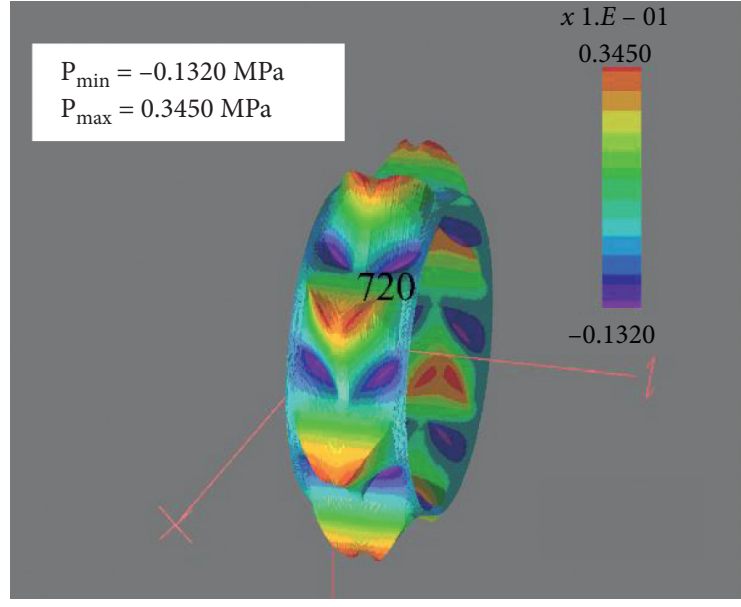

(b)

Figure 4: Pressure repartition (case C and case D, respectively). (a) Case C. (b) Case D.

herringbone angle ranging between $30^{\circ}$ and $40^{\circ}$. The results show that the best performance for a hydrodynamic herringbone bearing is the same amplitude angle.

Finally we have to note that the reliability of the results was achieved in the case of viscoseals. A study of the viscoseals in the case of different regimes (laminar, transition, turbulent) was carried out by [14]. The numerical results have been compared with the experimental results obtained by Luttrull [15] and show a good correspondence with those of the developed model.

3.3. Effect of the Grooves. To analyze the influence of the grooves width and depth, various numerical studies corresponding to different values of depth have been carried out.

3.3.1. Effect of the Grooves Width. Tables $2-4$ give, respectively, the effect of the grooves width (cases B, C, and D) on the maximum pressure, on friction torque, and on the fluid flow. The herringbone angle is given at $45^{\circ}$, the number of grooves $\mathrm{NG}=8, C=\mathrm{HG}=500 \mu \mathrm{m}$, and the rotational speed is constant at $25000 \mathrm{rpm}$.

In all cases, the maximum pressure and the friction torque values decrease with the increasing of the width of grooves. However, for the minimum pressure values, although they decrease with the width of grooves in case $\mathrm{C}$, they enhance slightly in both cases B and D. However, they are still not very significant and they are far from the cavitation effect.

To compare these results, in Table 2, the obtained results of the particular case (case A) have been added. The fluid flow seems less important compared with case $\mathrm{C}$, where it has been considered only a groove modeled in the middle of the bearing. As for the fluid flow values, they become null for a groove width greater than and equal to $0.5 \mathrm{~mm}$ in both cases B and D.

According to these results, the effect of grooves modeled at each side of the bearing has been clearly shown. The phenomenon of the axial flow leakage will be considerably reduced. These interesting results are in perfect concordance with Bootsma [2] work which has confirmed that the lubricant can be maintained in the groove without any sealing element. 


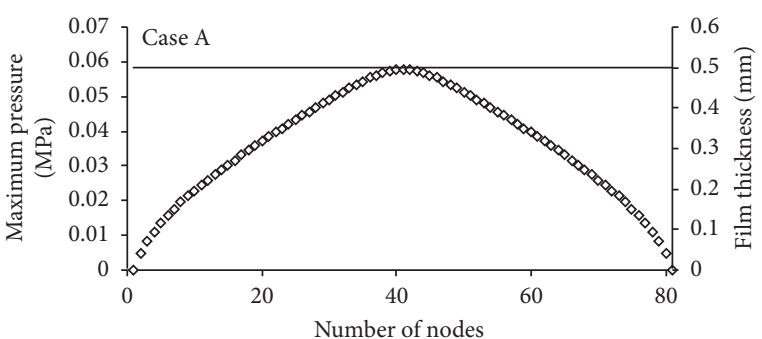

(a)

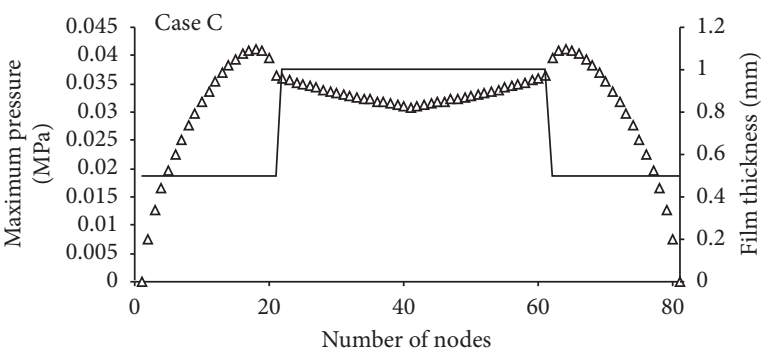

(c)

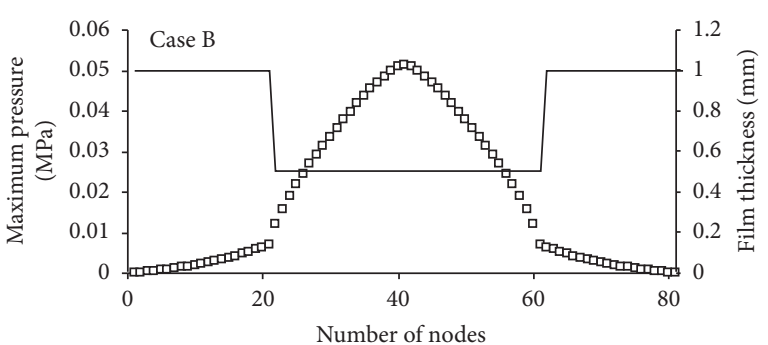

(b)

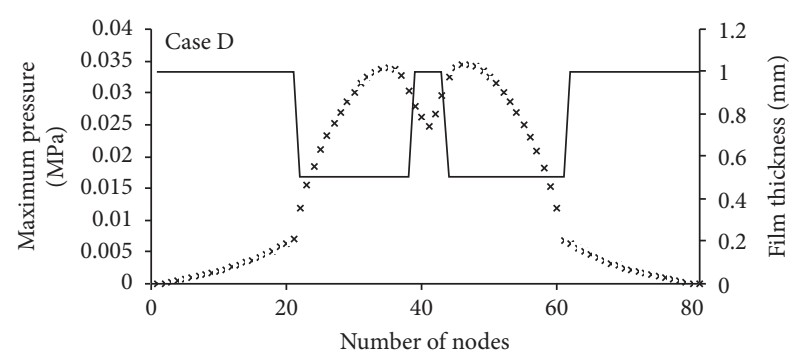

(d)

Figure 5: The maximum pressure and the film thickness versus the number of nodes for our geometries. (a) Case A. (b) Case B. (c) Case C. (d) Case D.

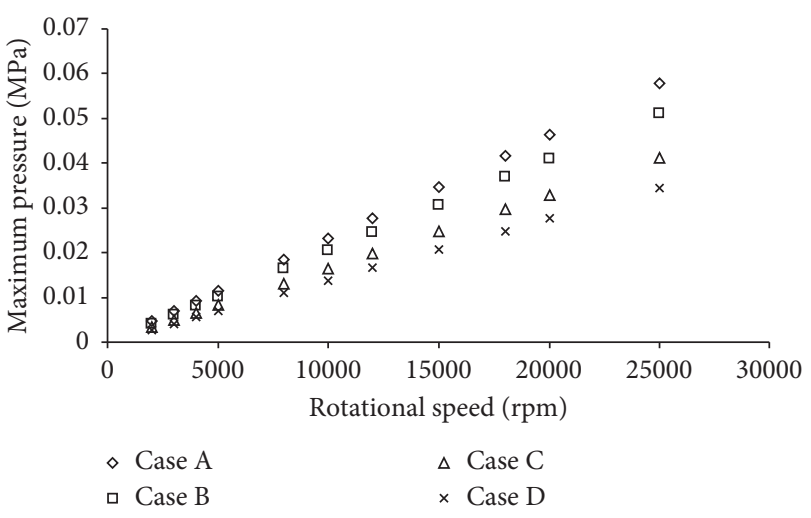

FIGURE 6: Variation of maximum pressure versus speed for different herringbone grooved journal bearings.

3.3.2. Influence of the Grooves Depth. For various grooves depths (HG from $0.01 \mathrm{~mm}$ to $0.1 \mathrm{~mm}$ ) (case A) with $\mathrm{NG}=8$, herringbone angle equal to $45^{\circ}$, and a clearance (C) constant $=500 \mu \mathrm{m}$, Figures $8-10$ give, respectively, the evolution of the maximum and/or the minimum pressure, the fluid flow, and the friction torque versus the rotational speed (from $2000 \mathrm{rpm}$ to $25000 \mathrm{rpm}$ ).

It can be noticed that the maximum pressure increases with the rotational speed and the increasing of the herringbone depth. Similar results were found for the minimum pressure and the fluid flow. However, there is no difference between the friction torque values. These results lead us to conclude that the speed has no effect on friction torque whatever the value of the groove depth is.

From this parametric study, we can say that the presence of grooves in a bearing reduces considerably the pressure and the axial leakage of the fluid.
3.3.3. Calculus of the Herringbone Grooved Bearings Stability. In the literature, it is well known that the herringbone grooved bearings, in addition to the role which they hold in reducing the fluid leakage, present a great stability compared to simple bearings.

We used Bootsma's work [2] for a spiral grooved bearing distinguishing between the situation where the load vector remains fixed and the case where it does not. The equations to calculate the admissible load $\mathrm{P}$, the friction losses $\mathrm{E}$, the eccentricity $e$, and the stability factor Mc, where Mc characterizes the stability compared to the half load, were given under the following:

For a fixed load vector,

$$
\begin{aligned}
P & =5 \frac{\eta \omega R^{4}}{(\Delta \mathrm{R})^{2}} \epsilon \quad \text { pour } \epsilon \leq 0,6, \\
E & =10 \frac{\eta \omega^{2} R^{4}}{(\Delta \mathrm{R})} \epsilon \quad \text { pour } \epsilon \leq 0,6, \\
M_{C} & =1,8 \quad \text { pour } \epsilon=0 .
\end{aligned}
$$

For a not fixed load vector,

$$
\begin{gathered}
P=4 \frac{\eta \omega R^{4}}{(\Delta \mathrm{R})^{2}} \epsilon \quad \text { pour } \epsilon \leq 0,6, \\
E=10 \frac{\eta \omega^{2} R^{4}}{(\Delta \mathrm{R})} \epsilon \quad \operatorname{pour} \epsilon \leq 0,7, \\
M_{C}=1,8 \quad \text { pour } \epsilon=0 . \\
M_{c}=m \omega(\Delta \mathrm{R})^{2} / \mu R^{4} \text { formula was taken from Muij- }
\end{gathered}
$$
derman's work [10]. 


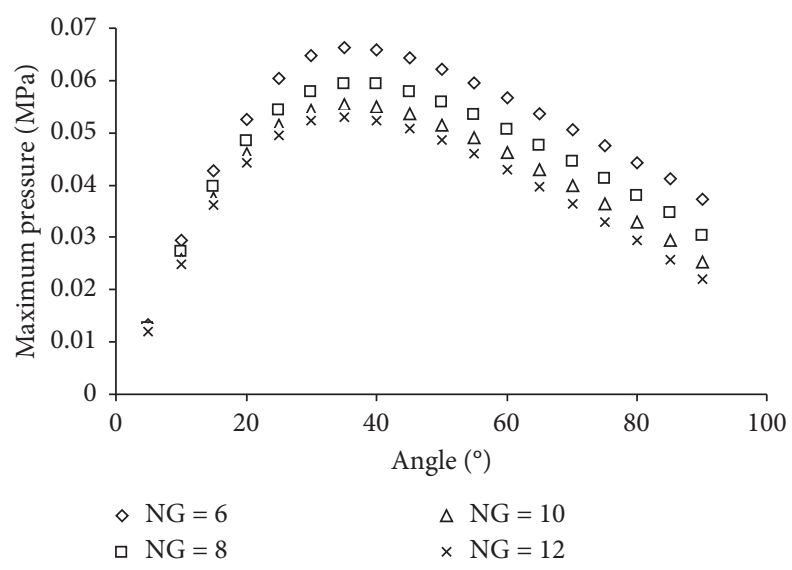

FIGURE 7: Variation of the maximum pressure versus the herringbone angles and the number of grooves.

TABLE 2: Effect of the grooves width (case B).

\begin{tabular}{lcccc}
\hline Width of grooves $(\mathrm{mm})$ & $P_{\min }(\mathrm{MPa})$ & $P_{\max }(\mathrm{MPa})$ & Friction torque $(\mathrm{Nmm})$ & Fluid flow $\left(\mathrm{mm}^{3} / \mathrm{s}\right)$ \\
\hline 0 (case A) & -0.011400 & 0.057894 & 349.74 & 95676.24 \\
0.2 & -0.011589 & 0.057296 & 349.42 & 0.03178 \\
0.5 & -0.011964 & 0.056388 & 345.22 & 0 \\
1 & -0.012597 & 0.054721 & 337.95 & 0 \\
1.5 & -0.013181 & 0.052952 & 330.46 & 0 \\
2 & -0.013696 & 0.051116 & 322.81 & 0 \\
\hline
\end{tabular}

TABLE 3: Effect of the grooves width (case C).

\begin{tabular}{lcccc}
\hline Width of grooves $(\mathrm{mm})$ & $P_{\min }(\mathrm{MPa})$ & $P_{\max }(\mathrm{MPa})$ & Friction torque $(\mathrm{Nmm})$ & Fluid flow $\left(\mathrm{mm}^{3} / \mathrm{s}\right)$ \\
\hline 0.2 & -0.011336 & 0.053758 & 349.38 & 168769.01 \\
0.5 & -0.011302 & 0.050236 & 345.86 & 166860.53 \\
1 & -0.011271 & 0.046353 & 340.58 & 163726.03 \\
1.5 & -0.011250 & 0.043435 & 335.68 & 160534.76 \\
2 & -0.011230 & 0.041114 & 331.00 & 157257.79 \\
\hline
\end{tabular}

TABLE 4: Effect of the grooves width (case D).

\begin{tabular}{lcccc}
\hline Width of grooves $(\mathrm{mm})$ & $P_{\min }(\mathrm{MPa})$ & $P_{\max }(\mathrm{MPa})$ & Friction torque $(\mathrm{Nmm})$ & Fluid flow $\left(\mathrm{mm}^{3} / \mathrm{s}\right)$ \\
\hline 0.2 & -0.011589 & 0.057296 & 349.42 & 0.03178 \\
0.5 & -0.011824 & 0.045243 & 336.07 & 0 \\
1 & -0.012401 & 0.043896 & 329.24 & 0 \\
1.5 & -0.012773 & 0.037534 & 314.01 & 0 \\
2 & -0.013250 & 0.034466 & 303.59 & 0 \\
\hline
\end{tabular}

For a bearing mass of $50 \mathrm{~g}$ and a rotational speed of $2000 \mathrm{rpm}$, the numerical calculation gives a value of $\mathrm{Mc}=1.004$. Compared to the critical value given by Bootsma, the obtained value is very low. That leads us to say that the herringbone grooved bearing, whatever its geometry is, holds its role of being very stable.

3.3.4. Effect of the Ratio $B_{0} / B_{T}$. Figure 11 presents the variation of the maximum pressure versus the ratio of the initial part of the shaft and the machined part (Figure 2), case A. The figure has a parabolic form with an optimal value around $0.057 \mathrm{MPa}$ at 0.5 . Below and above this value, the maximum pressure seems quasi-symmetrical; it increases between 0.1 and 0.5 and decreases beyond 0.5 . This result stays important in order to have optimal and coherent results.

3.4. Influence of the Eccentricity. In the previous sections we have supposed the ideal case when a bearing is centered on a shaft with an eccentricity equal to zero. In this section, we will suppose different values of axial eccentricity $\varepsilon_{\mathrm{x}}$ (from 0 to 0.6 ), with grooves width equal to $2 \mathrm{~mm}$, a constant rotational speed of $25000 \mathrm{rpm}$, a herringbone angle of $45^{\circ}$, and a radial clearance equal to $500 \mu \mathrm{m}$. 


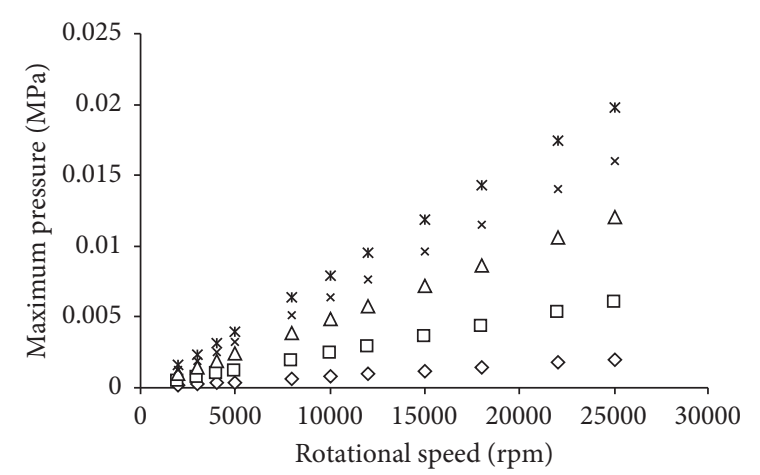

$\diamond \mathrm{HG}=0.01$

口 $\mathrm{HG}=0.03$

$\Delta \mathrm{HG}=0.06$

$\times \mathrm{HG}=0.08$

* $\mathrm{HG}=0.1$

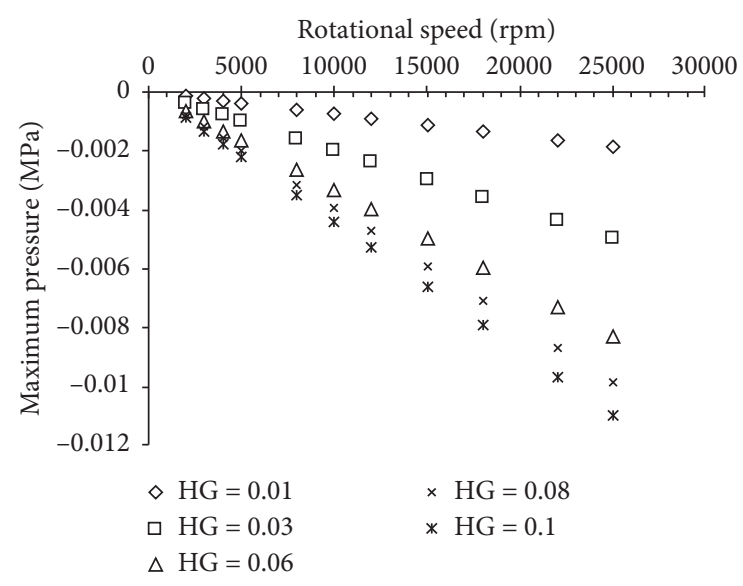

(b)

$\triangle \mathrm{HG}=0.06$

(a)

Figure 8: Effect of the grooves depth on pressure.

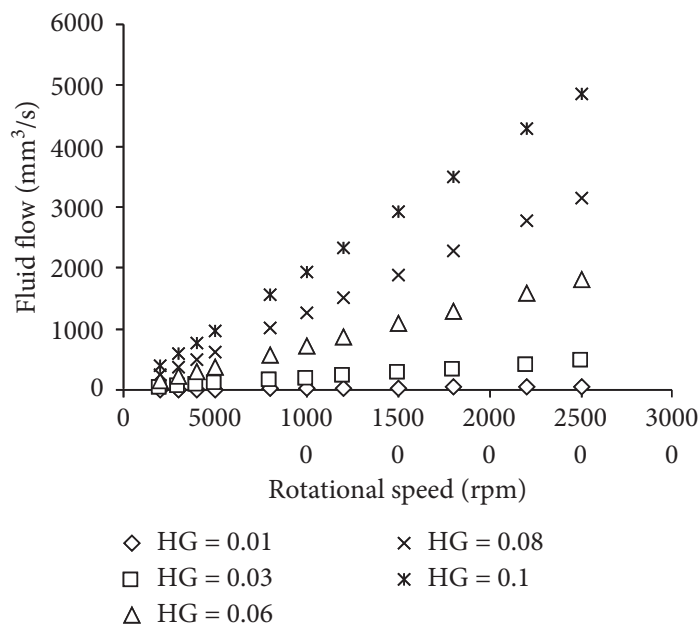

FIgURE 9: Effect of the grooves depth on fluid flow.

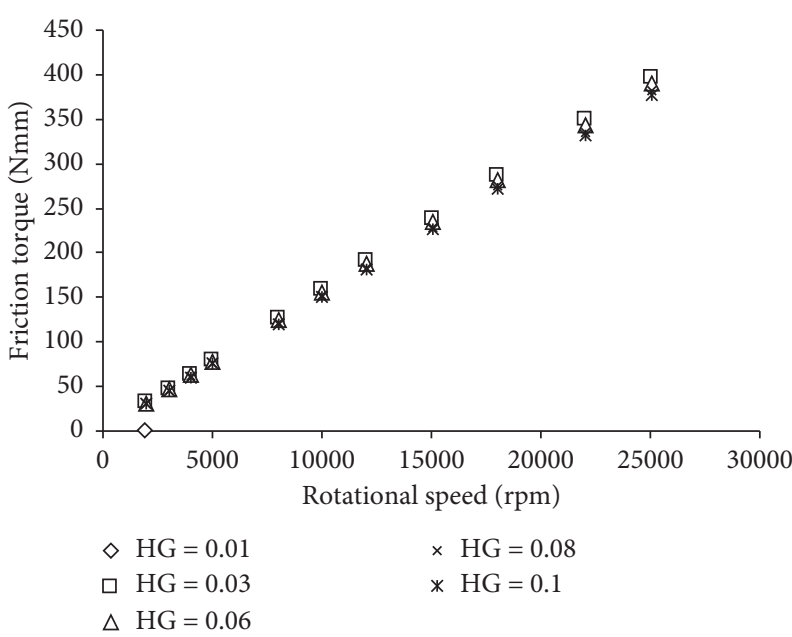

Figure 10: Effect of the grooves depth on friction torque. 


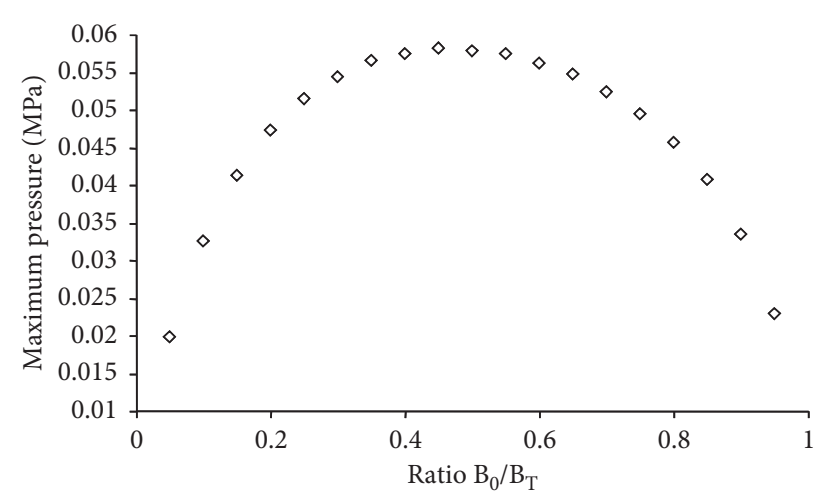

$\diamond$ Case A

Figure 11: Maximum pressure versus the ratio $\mathrm{B}_{0} / \mathrm{B}_{\mathrm{T}}$.

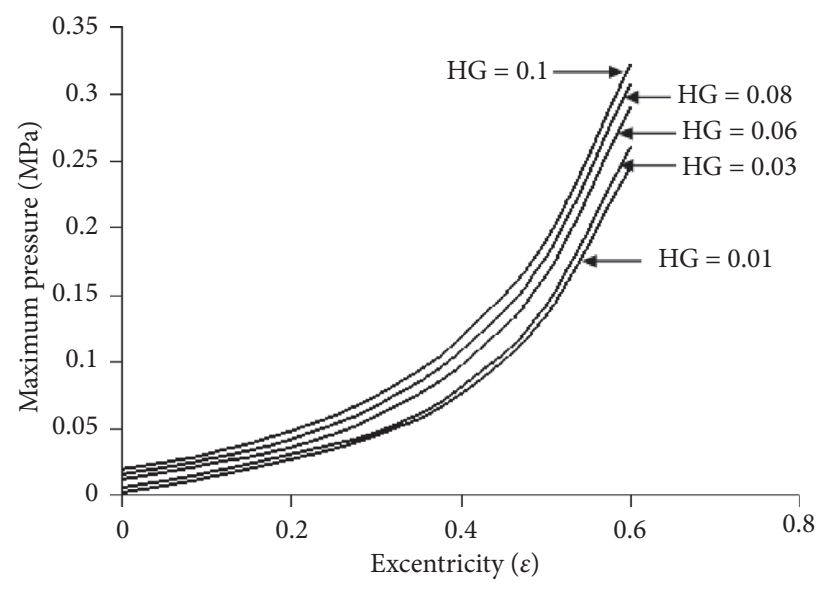

FIGURE 12: Variation of maximum pressure versus the eccentricity and the grooves depth.

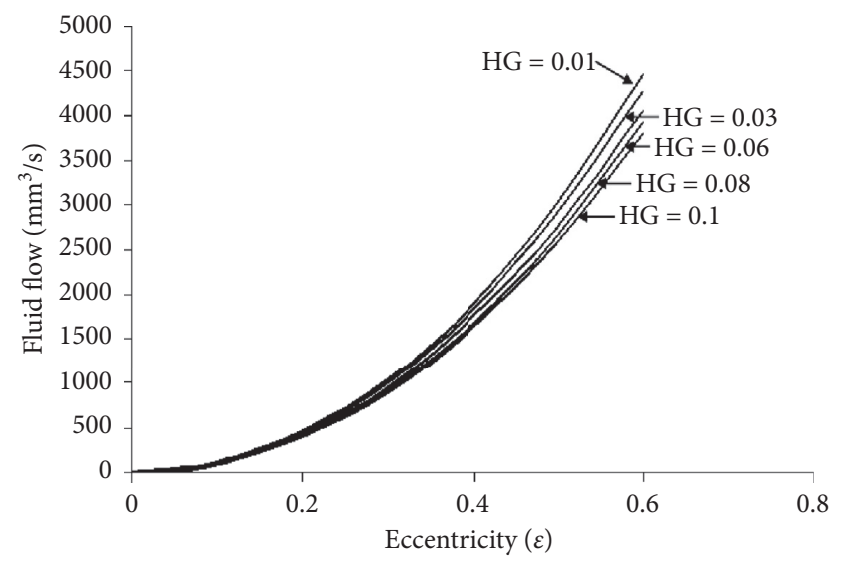

FIGURE 13: Variation of fluid flow versus the eccentricity and the grooves depth.

Figures 12 and 13, respectively, give the variation of the maximum pressure and the fluid flow versus the eccentricity and the grooves depth (Case B). It can be observed that the maximum pressure increases when the groove depth increases. Contrarily to the fluid flow, it increases when the groove depth decreases. The higher value of fluid flow is obtained at a groove depth of $\mathrm{HG}=$ $0.01 \mathrm{~mm}$. Of course that stays true for case D. 
Thus, considering higher values of grooves depth, the fluid flow can relatively be reduced whatever the value of the eccentricity is.

\section{Conclusion}

The present paper represents an important step toward our long term research goal of developing a numerical model capable of predicting herringbone grooved journal bearing performance with good accuracy, as it may prove very useful in sealing industry and (visco)seals designing. We investigated the mechanical herringbone performances using a combination of a hydrodynamic model and an adaptive mass conservative algorithm.

A numerical model has been developed by finite element method to solve the equation generating the phenomenon in order to calculate the pressure, the friction torque, and the fluid flow. Different herringbone geometry (circumferential width) and operating conditions were investigated. The principal obtained results have affirmed clearly that grooves modeled on bearings have the following effects

(i) They reduce significantly the axial fluid flow, which limits the phenomenon of the axial flow. This phenomenon could be an advantage to minimize the use of seals in systems when performing dynamic tests.

(ii) However, they reduce the maximum fluid pressure and the friction in contact and so reduce the thermal effect in the contact.

In conclusion, the herringbone grooved journal bearings, whatever their geometries are, play an important role in reducing the pressure and the fluid flow. That confirms our interest and the interest of the industries in using this type of element to guide devices requiring a high stability with very high rotation speed.

The study will be next extended to a numerical investigation of the influence of the thermal effects on the seal geometry and operating conditions on the pressure, the friction torque, and the fluid flow. A global thermal model will be used. In addition, the numerical model will be developed in order to determine the dynamics stiffness and damping coefficients.

\section{Nomenclature}

HG: Groove depth ( $\mathrm{mm})$

$\mathrm{B}_{0}$ : Initial part of the shaft

$\mathrm{B}_{\mathrm{T}}$ : $\quad$ Machined part

C: Nominal film clearance ( $\mathrm{mm}$ )

R: $\quad$ Radius of journal bearing ( $\mathrm{mm}$ )

$\mathrm{D}$ : Diameter of journal bearing $(\mathrm{mm})$

$\varepsilon_{\mathrm{x}}, \varepsilon_{\mathrm{z}}:$ Eccentricity in $x$ and $z$ direction

P: $\quad$ Pressure $(\mathrm{MPa})$

$\mu$ : $\quad$ Fluid viscosity (MPa.s)

$\omega: \quad$ Journal angular speed $(\mathrm{rd} / \mathrm{s})$

$\theta$ : Circumferential coordinate rotating with journal

$(\mathrm{x}, \mathrm{z})$ : Coordinate system attached to the grooved journal.

\section{Data Availability}

No data are included in the manuscript.

\section{Conflicts of Interest}

The authors declare that they have no conflicts of interest.

\section{Acknowledgments}

The authors would like to acknowledge "SKF France" for supporting this research project.

\section{References}

[1] G. G. Hirs, "The load capacity and stability characteristics of hydrodynamics grooved journal bearings," in Proceedings of the ASME-ASLE International Lubrication Conference, Washington, DC, USA, 1965.

[2] J. Bootsma and L. P. M. Tielemans, "Conditions of leakagefree operation of herringbone grooved journal bearings," Journal of Lubrication Technology, vol. 99, no. 2, pp. 215-222, 1977.

[3] M. M. Reddi, "Finite-element solution of the incompressible lubrication problem," Journal of Lubrication Technology, vol. 91, no. 3, pp. 524-533, 1969.

[4] B. J. Hamrock and D. P. Fleming, "Optimization of SelfActing Herringbone Grooved Journal Bearings for Maximum Radial Load Capacity," in Proceedings of the 5th Gas Bearing Symposium, Southampton, UK, March 1971.

[5] A. J. Smalley, "The narrow groove theory of spiral grooved gas bearings: development and application of a genearlized formulation for numerical solution," ASME Journal of Lubrication Technology, vol. 94, pp. 86-92, 1972.

[6] D. Bonneau and J. Absi, "Analysis of aerodynamic journal bearings with small number of herringbone grooves by finite element method," Journal of Tribology, vol. 116, no. 4, pp. 698-704, 1994.

[7] C.-C. Wang, "Bifurcation analysis of an aerodynamic journal bearing system considering the effect of stationary herringbone grooves," Chaos, Solitons \& Fractals, vol. 33, no. 5, pp. 1532-1545, 2007.

[8] G. H. Hang and J. W. Yoon, "Nonlinear dynamic analysis of a hydrodynamic journal bearing considering the effect of a rotating or stationary herringbone groove," ASME Journal of Tribology, vol. 124, pp. 297-304, 2002.

[9] J. Absi, Les paliers à rainures: approche expérimentale et simulation numérique, Ph.D. thesis, Université de Poitiers, Poitiers, France, 1994.

[10] E. A. Muijderman, "Grease lubricated spiral groove bearings," Tribology International, vol. 12, no. 3, pp. 131-137, 1979.

[11] M. Targaoui, D. Souchet, and F. Bouyahia, "On the hydrodynamic sealing in lubricated viscoseal," Tribology Transactions, vol. 58, no. 3, pp. 527-536, 2015.

[12] M. Hajjam and D. Bonneau, "A transient finite element cavitation algorithm with application to radial lip sealsfinite element cavitation algorithm with application to radial lip seals," Tribology International, vol. 40, no. 8, pp. 1258-1269, 2007.

[13] E. F. Boon and S. E. Tall, "Hydrodynamische Dichtung für rotierende Wellen," Chemie Ingenieur Technik-CIT, vol. 31, no. 3, pp. 202-213, 1959.

[14] D. Souchet, M. Jarray, A. Fatu, and april, "Performance characteristics of viscoseals in laminar and turbulent flow 
regimes," Tribology International, vol. 114, pp. pp152-160, 2017.

[15] L. H. Luttrull, "Study of convective inertia effects and methods of controlling gas ingestion in large diameter viscoseals," Report NGR-43-001-003, University of Tennessee, Knoxville, Tennessee, 1970.

[16] D. Bonneau, A. Fatu, and D. Souchet, Hermes-lavoisier, Interaction Design Foundation, Aarhus, Denmark, 2011.

[17] Y. Han, S. Xiong, J. Wang et al., "A new singularity treatment approach for journal-bearing mixed lubrication modeled by the finite difference method with a herringbone mesh," Journal of Tribology, vol. 138, no. 1, 2016.

[18] Y. Han, J. Wang, G. Zhou, K. Xiao, and J. Li, "Micro-bottom shape effects on the misaligned herringbone grooved axial piston bearing with a new parallel algorithm," Proceedings of the Institution of Mechanical Engineers, Part J: Journal of Engineering Tribology, vol. 231, no. 5, pp. 637-654, 2017.

[19] G. Xiang, Y. Han, J. Wang, K. Xiao, and J. Li, "A transient hydrodynamic lubrication comparative analysis for misaligned micro-grooved bearing considering axial reciprocating movement of shaft," Tribology International, vol. 132, pp. 11-23, 2019. 